\section{LA CIENCIA Y EL ARTE DESDE LA PERSPECTIVA DE LA TRANSEVOLUCIÓN}

\author{
Andrés Moya \\ Universidad de Valencia \\ ORCID ID: https://orcid.org/0000-0002-2867-1119 \\ andres.moya@uv.es
}

\section{SCIENCE AND ART FROM A TRANSEVOLUTIONARY PERSPECTIVE}

Cómo citar este artículo/Citation: Moya, A. (2018). La ciencia y el arte desde la perspectiva de la transevolución. Arbor, 194 (790): a477. https://doi.org/10.3989/arbor.2018.790n4002
Copyright: (C) 2018 CSIC. Este es un artículo de acceso abierto distribuido bajo los términos de la licencia de uso y distribución Creative Commons Reconocimiento 4.0 Internacional (CC BY 4.0).
RESUMEN: La especie humana ha manipulado desde sus orígenes tanto el mundo real como el figurado. Mientras que la acción manipuladora de la especie humana sobre ambos mundos fue crítica para su supervivencia al comienzo de su evolución -hoy transevolución-, en la cultura ulterior esos mundos son abordados por dos actividades con bases conceptuales muy diferentes: la ciencia y el arte. En este trabajo sostengo la tesis de que ambos resultan necesarios para saber estar en el mundo y para transformarlo adecuadamente.

PALABRAS CLAVE: Ciencia; arte; verdad; desocultamiento; manipulación; transformación; transevolución.
ABSTRACT: From its origins, the human species has manipulated not only the real world but also the figurative one. While that manipulative action of the human species over both worlds was critical for the survival of the species in the beginning of its evolution -now transevolution-, it is also true that in the subsequent culture those worlds have been approached by two trades with highly different conceptual bases, science and art. In this paper I hold the thesis that both trades are necessary to know how to be in the world as well as how to transform it in an appropriate way.

KEYWORDS: Science; art; truth; revealing; manipulation; transformation; transevolution. 


\section{DE LA INTUICIÓN AL OFICIO}

Si en lugar de examinar la ciencia por su producto o por su proceso lo hiciéramos atendiendo a la intuición, a la idea o al ansia por comprender que están detrás de ella, nos daríamos cuenta, como probablemente no pueda ser de otra manera, de que no difiere mucho de otras actividades del pensamiento. No es que la existencia llegue a cobrar sentido para el individuo que examina el mundo bajo el prisma de la ciencia, pero proporciona satisfacción y deleite intelectual conocer las piezas que lo componen y que lo hacen funcionar. En el fondo, sean reales o figurados sus respectivos mundos, y con independencia también de si por la ciencia accedemos o no al único mundo real posible, cuestión de eterno debate, la ciencia y las artes convergen en un hedonismo palmario y consustancial en sus practicantes: los científicos y los artistas. De nuevo, sean reales o figurados, a los mundos se accede en primera instancia a través de la intuición, la idea y la voluntad de comprenderlos. El sentido ganado por el mundo real o el mundo figurado gracias a la explicación que sobre ellos elabora el científico o el artista quizá no sea transferible sin más a la existencia de estos, pero eso es otro asunto y en todo caso científico y artista sí disfrutan por la cosa hecha, algo consustancial a nuestra especie. Luego están los métodos, las especializaciones, las matemáticas, las metáforas y las adecuaciones de las diferentes ciencias y artes que conforman los aprendizajes y los oficios, de cuyo ejercicio más o menos diestro obtendremos un mayor o menor placer final.

Nuestra especie manipula desde sus orígenes los entes del mundo, tanto los del real como los del figurado. $Y$ ese trabajo inicial no se puede considerar estrictamente científico, pero tampoco estrictamente artístico. El objetivo que subyacía a la manipulación de las cosas reales del mundo y de las cosas figuradas era posibilitarnos la supervivencia por la apropiación de las mismas. Hay cuestiones ontológicas que ya nos preocupan desde entonces y, al tiempo que tratábamos de subsistir manejando los entes del mundo real, también las creaciones del mundo figurado respondían a cierta necesidad de atribuir sentido a la existencia. La representación figurada de un animal no era otra cosa que un intento por aprehenderlo y dominarlo en cierta forma, por ejemplo. Ese sentido existencial tiene más relación con las ganas de vivir y sobrevivir, es decir con la aludida perduración de los miembros de la especie, de lo que estaríamos dispuestos a aceptar de entrada. No había todavía ciencia de las manipulaciones ni, verosímilmente tampoco, arte, sino más bien tentativas de mantenerse por medio de prácticas de racionalidad mínima sobre el mundo real (a base de ensayo y error), así como balbucientes vislumbres de un mundo imaginario que pretendía captar la esencia de las cosas. No creo que lo primero fuera ciencia todavía, ni arte lo segundo. La ciencia y el arte se forjaron posteriormente con la propia evolución de la cultura, y de la intuición para las cosas de los mundos real y figurado pasamos a los oficios. Pero ¿en qué consisten ese oficio al que llamamos ciencia, y ese otro al que denominamos arte?

\section{NUESTRA SINGULARIDAD}

El hombre es la única especie que puede repasar su historia y cuyos miembros pueden reflexionar, con estupor unos y con satisfacción otros, sobre el hecho de que de la misma forma que hemos llegado a ser podríamos no haber llegado. Esta constituiría una de las más crudas conclusiones existenciales que cabría esperar de la moderna teoría de la evolución. No obstante, tales afirmaciones requieren matización. La teoría evolutiva, en efecto, es uno de los pilares centrales de la moderna biología, la ciencia que estudia los entes vivos. Y esa teoría, cuya formulación inicial corre a cargo de Darwin, avanza que todos los entes vivos tienen un origen común y que unos vienen de la evolución de otros. La especie humana no es ajena en modo alguno al devenir evolutivo, y la moderna investigación biológica confirma, primero, que la enorme cantidad de caracteres idénticos entre todos los entes vivos solamente es explicable por la circunstancia de que todos procedemos de un ente ancestral común; y segundo, que rastreando los caracteres de nuestra especie, así como los de otras, somos capaces de reconstruir con precisión creciente la historia evolutiva que nos precede. Sería sumamente oportuno, por otra parte, atender a la historia de esa reconstrucción, porque cuando examinamos las especies vivas que están próximas a nosotros en el árbol evolutivo, u otras ya desaparecidas, apreciamos que comparten, o han compartido con la nuestra, una ingente cantidad de caracteres. Muchos de dichos caracteres son constitutivos del ente humano, de la misma forma que de esas otras especies, simplemente porque los hemos heredado de los ancestros comunes. Otros son inéditos, y tiene relevancia detectar su aparición. Así pues, los entes que son las especies se componen de caracteres compartidos y de caracteres novedosos. Aunque los caracteres particulares o específicos de las especies nos sirvan para la discriminación sistemática entre ellas, si es que estamos dispuestos a conferir estatus de ente definido a cada especie, lo cierto es que no es 
lícito obviar la importancia que revisten los caracteres compartidos como prueba fehaciente de que todas poseen un mismo origen y genealogía. No podemos tampoco hacer caso omiso del hecho de que los entes vivos son susceptibles de transformarse con el devenir del tiempo, y es un objetivo fundamental de la ciencia que los estudia determinar qué agentes, qué fuerzas guían, sin dirección aparente, la transformación de unos en otros. Darwin fue diestro proponiendo una de ellas, la selección natural. No es la única: existen otras. De hecho, para Darwin era imperiosa la necesidad, dada la natural transformación de unos entes en otros, de hallar de nuevo alguna fuerza, también natural, apta para explicar la evolución.

Es probable que nos aturda la diversidad de lo vivo; casi no hay rincón en el planeta que no esté habitado por la vida, y sorprende conocer las condiciones tan extremas, desde una perspectiva antropocéntrica, que aquella puede llegar a soportar. Por poco que se estudie su naturaleza y las fuerzas que gobiernan su evolución, no dejaremos de apreciar la irreductible tendencia de lo vivo a perseverar, haciendo de la transformación, de la diversificación y, en una palabra, del cambio, la base de su éxito colonizador y expansivo. Cualquier ontología de la vida debería captar tan inexcusable cualidad.

Pero regresemos a la primera afirmación: el hombre es la única especie capaz de reconstruir su historia evolutiva. Esta no es sino una más de las muchas investigaciones desarrolladas por la especie dentro de la esfera del conocimiento que llamamos ciencia. Y la ciencia es, también, otra de las muestras posibles del repertorio de capacidades intelectivas de nuestra especie. Algo ha acontecido en su singular evolución que ha posibilitado a la especie humana ser destacadamente racional e inteligente. Con todo, no conviene enfatizar tal circunstancia desde la óptica de la exclusividad. Si deseamos contemplar la evolución como una categoría intrínseca a la vida, cosa innegable, entonces deberíamos admitir que la inteligencia, la racionalidad y otras características que nos solemos atribuir como privativas no lo son en realidad -aun cuando sí pueda serlo un cierto grado de ellas-. En todo caso, hemos conseguido narrar la historia de la vida en el planeta y, específicamente, nuestra propia historia evolutiva. No se trata de una conquista antigua pues, aunque la ciencia moderna nace con Galileo en el siglo XVI, el descubrimiento de la evolución, del árbol de la vida y de la historia evolutiva de nuestra especie tardarían al menos tres siglos más. Son hechos relativamente recientes $y$, además, muy descollantes porque trascienden su propia facticidad. En efecto, cuando enjuiciamos racionalmente parejos hallazgos no podemos dejar de reflexionar sobre su significación. Formulo una de esas reflexiones, de marcado interés para lo que aquí pretendo, mediante las siguientes preguntas: ¿por qué hemos llegado a ser entes tan racionales?, ¿de qué nos sirve?, ¿qué hacer con nuestra inteligencia? Mi interrogación sobre el servicio que la inteligencia presta a la especie no tiene por finalidad mostrar que con ella hacemos cosas, como de hecho ocurre y siempre ha ocurrido. Sin ir más lejos, somos una especie sorprendentemente activa en su competencia para modificar o alterar el medio que la rodea, ahora ya casi todo el planeta. Sostengo, además, que el intervencionismo es crecientemente racional o, dicho de otro modo, progresivamente más científico conforme la ciencia va proyectando su linterna del conocimiento sobre los entes que constituyen la naturaleza, entes entre los que nos contamos. Nuestra especie, con su razón científica, ha intervenido e interviene la naturaleza, incluida la nuestra. No obstante, mi pregunta por el activo servicio que la inteligencia nos presta pretende ser un cuestionamiento de otro tipo, a saber: ¿puede nuestra singular inteligencia trascender la naturaleza de los entes? Y ¿qué entiendo por trascender? No utilizo el término en el sentido kantiano de traspasar los límites de toda experiencia posible, sino más bien en una doble acepción muy vinculada a la ciencia misma y próxima al realismo de Heidegger. Por un lado, trascender en el sentido de penetrar, comprender o averiguar algo que está oculto. La inteligencia, como instrumento de la ciencia, sujeta los entes a una actividad de escrutinio, de experimentación, que los desoculta y que los hace comprensibles. Si declaro que los hace más comprensibles es que ya disponemos previamente de esa misma capacidad de desocultamiento; pero la inteligencia en su vertiente científica acentúa la comprensión de los entes y, por lo tanto, los torna más manejables, mediante un mayor entendimiento de lo que sobre ellos pudiera obrarse. De no estar la acción rodeada de tanta inteligencia, de no estribar en el desocultamiento científico de la verdad del ente, no se lograría manipular este último. Por otro lado, la segunda acepción de trascender, muy próxima al aserto que acabo de efectuar, es la de que con la acción científica inteligente vamos más allá del propio ente comprendido o penetrado. La ciencia se configura como práctica inteligente, y trasciende los entes sobre los que proyecta su linterna, en el sentido de moverse allende ellos, de transformarlos, de crear o fabricar otros. 


\section{LA ESPECIALIZACIÓN DE LA CIENCIA}

En una obra en la que se ocupa de la esencia de la ciencia, Heidegger (1999) reconoce que para tratar tal materia hay que plantearse antes otras preguntas. La primera, por ejemplo, versaría sobre la relación que existe entre el ser con capacidad de conocer y los entes conocibles. Del primero, el hombre, asevera Heidegger que su existir o Dasein lo faculta para apreciar el ente cual ente, el ente verdadero. No cabe relativismo en el conocimiento debido a la inconfundible forma en que nos relacionamos con el resto de seres de nuestra especie y con los entes en general. Heidegger otorga singularidad a la especie; el Dasein de los humanos es único, tiene carácter de exclusividad, marca propia que bien pudiera vincularse a la autoconciencia, a la percepción de "yoidad", de ser el único ser que se pregunta por el ser, por su ser, hallándose su esencia en su propia existencia. Yo, por mi parte, pienso que la ontología de la vida reclamaría que algo tan fundamental como el Dasein (humano) fuera una característica compartida, hasta cierto grado, con otros seres que, evolutivamente, están próximos a nosotros. Sin embargo, no es esa la cuestión que deseo abordar y desarrollar aquí. Lo que me interesa subrayar, desde una óptica más científica, es si el Dasein humano, aun y admitiendo que sea exclusivo, constituye o no el producto esperable de cualquier evolución natural. Anteriormente había descrito como grandes éxitos en la biología el descubrimiento del árbol de la vida o de la historia evolutiva de la especie humana, historia donde se pone de manifiesto que somos entes naturales con caracteres tanto compartidos con el resto de las especies como singulares. Un punto que sigue en debate es si nuestra especie es un producto final de la evolución o, por el contrario, otro resultado singular de la misma, por maravillosas que pudieran parecer las cualidades que la configuran. No descarto que consigamos llegar en algún momento a una dilucidación efectiva de tal asunto desde la ciencia, desocultando cada vez más ese ente tan particular que es la especie humana. La cuestión en torno a si somos o no un producto final, complejo, de la evolución biológica, divide a muchos estudiosos, tanto dentro de la ciencia como fuera de ella. Dentro de la ciencia, por ejemplo, la posición tradicional de los biólogos evolutivos es que somos meros accidentes, y que las contingencias que gobiernan la evolución hacen totalmente imposible pensar en una tendencia hacia entes de complejidad progresiva, cuyo término más acabado sería nuestra especie. En cambio, desde otros sectores de la ciencia, señaladamente desde la física y su célebre principio antrópico, se asegura que cualquier teoría válida sobre el universo tiene que ser compatible con la existencia del hombre. Es decir: si en el universo se deben verificar ciertas condiciones para nuestra existencia, esas condiciones son verdaderas porque nosotros existimos. $Y$ diversas corrientes de pensamiento evolutivo relativamente jóvenes postulan también que es inevitable la complejidad creciente de la vida en su evolución, a pesar de la supuesta contingencia y no predictibilidad local o puntual, tanto espacial como temporal, del devenir evolutivo. Estas corrientes no entran en consideraciones más especulativas en torno a si el hombre es el remate de la evolución biológica, o la complejidad creciente la forma contemporánea de hablar científicamente sobre el progreso; simplemente manifiestan que pertenece a la dinámica de la vida incrementar su complejidad, y que cualquier contingencia que la mermase, o cualquier fuerza temporal que la redujera, tarde o temprano se vería contrarrestada de nuevo por la propensión natural a la complejificación. Es más, empezamos a encontrar formulaciones teóricas sobre las condiciones necesarias para que la evolución sea progresiva y, lo que resulta más importante, predecible. Sé que estas hipótesis pueden antojarse al menos sorprendentes cuando uno se da cuenta de cómo se suele estudiar, explicar y presentar la historia evolutiva, generalmente imbuida de los principios básicos de contingencia y accidentalidad, que hacen francamente impracticable toda referencia a principios alternativos como los de complejidad creciente, inevitabilidad o progreso.

En tanto en cuanto sigamos adelantando en el desocultamiento esencial del recorrido evolutivo, especialmente en el desarrollo de una teoría universal más acabada de la evolución, bien predictiva o bien no predictiva, será oportuno desarrollar el pensamiento sobre la trascendencia del quehacer humano atendiendo a su propio futuro, pensamiento que se basaría en dos supuestos primordiales. El primero de ellos es el de nuestra singularidad como seres capaces de asegurar sin ningún género de dudas, al menos retrospectivamente, que "estamos aquí", que "somos conscientes de ser", y que estamos aquí porque hay un proceso, de asumida complejidad creciente, basado en la acción sistemática de fuerzas puramente naturales, que nos ha llevado a la situación de ser conscientes de nuestra existencia, así como a poder establecer nuestra genealogía vital, la que nos vincula con el resto de entes que pueblan o han poblado el planeta. El segundo supuesto concierne a la misma ciencia -genuino producto de la racionalidad y de la inteligencia-, la cual, siendo una conquista reciente, nos lleva de la mano hacia la trans- 
formación racional de la naturaleza, incluida la propia (Fernández Liria, 2012). Este supuesto tiene amplias consecuencias, por lo que, al igual que sucede con el supuesto previo, no hemos de tomarlo como carente de soporte empírico. Ambos disponen de él. En efecto, es empíricamente contrastable que somos un resultado de la evolución biológica en relación de parentesco con el resto de entes vivos (dicho esto, nos falta soporte, ya se apuntó, para confirmar si encarnamos el producto final de la evolución, la forma más avanzada de la complejidad o del progreso biológico ascendentes). También es empíricamente contrastable que nuestra especie ha intervenido e interviene en la naturaleza de modo cada vez más racional, más científico. Somos interventores compulsivos, pero solo podemos efectuar especulaciones -en parte justificadas por la historia de los logros sociales, culturales, científicos y tecnológicos de las diferentes civilizaciones- a propósito de qué futuro cabe augurar para nuestro planeta y para los entes que lo pueblan, así como para nosotros mismos.

Los dos supuestos anteriores conforman la base que me ha ayudado a formular la tesis sobre la trascendencia de la evolución a la que denomino, en una sola palabra, transevolución. Conviene hacer una consideración previa para evitar confusiones sobre lo que significa, en primera instancia, la trascendencia de la evolución como teoría científica que ha ido más allá de su propio dominio biológico para entrar en el dominio no-biológico, tecnológico y cultural si se quiere, de la transevolución. La evolución biológica, en cuanto teoría, ha sobrepasado su propio campo de actuación, y en torno a ella se ha forjado un pensamiento evolutivo que permea, que impregna, muchos otros saberes y disciplinas. El pensamiento evolutivo elabora explicaciones convincentes, racionales, en torno al lenguaje, la ética, la religión, la sociedad o la economía. C. Castrodeza (2010), por ejemplo, eleva la selección natural a categoría metafísica. Así, las conductas sociales de los individuos en sectores o profesiones o colectivos tan variados como los de la política, la economía, las naciones, las culturas o las lenguas, etc., parecen admitir, todas ellas, una razonable interpretación sobre el supuesto nada desdeñable de que están darwinizadas, de que son darwinianas en esencia. Es decir, de que su dinámica responde a una acción selectiva que, en condiciones de competencia por recursos obviamente escasos, impone el dominio de unos individuos sobre otros, de los partícipes de unas ideas o representantes de una clase política sobre los de otra, de los seguidores o impulsores de unas economías frente a los de otras, de los miembros de unas naciones sobre los de otras, de los poseedores de una cultura o de los hablantes de una lengua dadas sobre los de otras. Es cuestión clave identificar la naturaleza del recurso que corresponde a cada uno de esos ámbitos, profesiones o colectivos, cuya escasez promueve la acción de la selección natural. Ahora bien, ¿̇son los individuos los últimos beneficiarios de tal imposición? Castrodeza sostiene que no porque, aunque se trate de seres humanos concretos en cualquier zona de la sociedad, en la política, en la economía, en la ciencia, o en un país o en otro, en esta o aquella lengua, etc., los que en verdad se imponen unos a otros no son los individuos, sino sus genes, que simplemente tratan de maximizar su eficacia, de extenderse. Llevando hasta límites extremos la tesis de Dawkins relativa a los replicadores, para Castrodeza el ente humano no representaría más que un feliz constructo de la evolución biológica, en el cual la conciencia del yo, la percepción de ser único, es un invento de la evolución por selección natural para garantizar la persistencia temporal de sus replicadores más íntimos e indivisibles. Obviamente esta tesis, que conduce al nihilismo absoluto, comporta que todas las más nobles cualidades de la especie no dejan de ser un cúmulo de sucesivas y afortunadas soluciones rematadas en el autoengaño del ente sobre su yo, sobre su ficticio control de sí mismo y sobre su presunta voluntad de decidir con libertad. Visión del ente humano que, como no parece compatible con el Dasein heideggeriano, nos empujaría a plantearnos el otorgar tal estatus existencial a sus unidades más fundamentales e indivisibles: los genes. ¿Habría alguna contra-argumentación pensable, alguna tesis a nuestro alcance que permitiera subvertir el nihilismo impuesto por los genes al ente humano y, en general, al resto de entes vivos? Es probable que la respuesta se halle en la misma historia reciente de la ciencia, en el surgimiento de la biología molecular y de la ingeniería genética, en ese preciso momento en el que los propios genes se vuelven entes ellos mismos intervenibles a partir de su construcción más sofisticada y perfecta: la especie humana. La capacidad de nuestra especie para modificar la naturaleza ha sido una tónica constante, pero si siguiéramos a pies juntillas la tesis de los replicadores dawkinianos acabaríamos por mantener que todo ese intervencionismo, de una manera u otra, estaba en último término orientado a la maximización del éxito relativo de unos replicadores frente a otros, y no de los individuos. Y tal vez sea legítimo afirmar que todavía permanecemos bajo su ciego influjo, al menos mientras no intensifiquemos nuestra acción sobre ellos. Solo con la actual ciencia biológica vislumbramos que podemos lograr esto último. No lo estamos haciendo con nuestro propio genoma, en toda su dimensión, 
porque el trecho que nos separa de una intervención racional, efectiva, inteligente sobre él es todavía largo. Pero el resto de entes vivos ya son objeto de nuestro actuar interventor. La domesticación de especies con las que convivimos ilustra la acción trascendente sobre los otros entes vivos, intervención que va nutriéndose continuamente de ciencia. Tanto es así que estamos a las puertas de crear, de fabricar entes que no han existido antes, y eso aun cuando una ciencia como la biología sintética se encuentre solamente en sus albores ¿Qué tipo de biología cabe esperar, en el futuro más o menos inmediato, que concierna también a un intervencionismo de gran calado sobre el propio ente humano? Si aceptamos la tesis nihilista de los replicadores dawkinianos, el subsiguiente análisis filosófico del estatuto del ente humano y de su intervencionismo sobre otros entes y sobre el suyo propio nos informa de que el Dasein del hombre está por constituirse, y de que será real cuando tengamos una capacidad de intervención racional y con amplio desocultamiento sobre nosotros mismos, en particular sobre nuestros genes. La intervención sobre el resto de los entes, nuestra proyección científica hacia los mismos a partir de la emergencia de la ingeniería genética, su gradual desocultamiento, no es otra cosa que el mejor ejercicio, la antesala para superar el nihilismo y para entrar en la fase propiamente existencial del ser humano; para exceder así, o eliminar, el estatus de Dasein existencial de sus replicadores. Y es aquí donde comparece la idea de trascender la evolución como transevolución por acción del, ahora sí, Dasein humano.

Con la tesis de la transevolución sostengo que el hombre está en condiciones de trascender la naturaleza, incluida la suya propia. De hecho, podría afirmarse que es sustancial, esencial a nuestra especie, llevar a cabo tal proceso, como venimos haciéndolo desde nuestro origen. Es más, se conseguirá guiar la transformación de la naturaleza según modalidades que solo podemos barruntar, aunque existen algunas sólidas evidencias -las antes comentadas como soporte empírico a los dos supuestos- que nos llevan a presagiar sociedades, mundos y entes radicalmente nuevos. El segundo supuesto se sirve de la ciencia, y hace que ella asuma un protagonismo central en toda esta empresa transformadora y reinterpretativa de los entes. Fue Heidegger mismo quien otorgó a la ciencia, cuando perseguía su esencia, una cualificación y una relevancia que la sitúa no como una manera entre otras de desocultar la verdad de los entes, sino como el instrumento más valioso al que podemos recurrir para alcanzarlo.

\section{CIENCIA Y CONOCIMIENTO GENERAL}

Desde sectores diferentes al campo científico se afirma que la ciencia no es más que un modo de conocer la naturaleza y los entes que la constituyen. La aprehensión de esos entes, aseveran portavoces no científicos, puede llevarse a cabo a partir de otros regímenes de conocimiento con capacidad de captación de la realidad del mundo o de la esencia de las cosas. Si bien doy por buena tal afirmación, creo que sería razonable utilizar, en un intento aclaratorio y clasificatorio de tales sistemas de aprehensión del mundo, precisamente su estatus o no de cientificidad porque, a mi juicio, hay una diferencia entre el quehacer científico y el no científico. Bajo el paraguas de la no cientificidad se protegen muchas formas de aferrar el mundo, la esencia de los entes, las cuales, tal y como defiende Heidegger, quizá gozan de habilidad similar a la de la ciencia para dar, desde el Dasein, con la verdad entitativa. Los atributos de verdad del ente desocultado ya están ahí desde el primer momento, y la percepción de cualquiera de ellos mediante el arte, la poesía o la filosofía, puede ser incluso sublime. La ciencia, en cambio, suele provenir de una captación pobre de los atributos de los entes, más alejada en principio de lo fundamental que la de la literatura, el pensamiento filosófico y las artes. De hecho, la proyección científica sobre los entes resulta siempre tosca, limitada y parcial. Ello es así porque la ciencia no puede, en su estricta identidad, abarcar el estudio del ente en cuanto ente, desligado de sus atributos, que son por fuerza aquello en lo que la ciencia se focaliza y se especializa. Esa es la diferencia cardinal entre la filosofía o el arte y la ciencia. Pero la ciencia dispone de un proceder, de un método, que la lleva invariablemente, de forma progresiva y sistemática, a un tipo de desocultamiento de la verdad subyacente de los entes que por su parte no tiene parangón posible con los asimientos instantáneos de la poesía, la literatura o la música. El mismo Heidegger considera que, con la ciencia, hemos fabricado un instrumento imprescindible que nos proporciona una capacidad de intervención sobre los entes de la que, probablemente, carecen las otras formas no científicas de aprehensión de la realidad y del mundo. Aun cuando estas últimas, que continúan tras el auge de la ciencia, ayudan a saber qué tenemos delante, a entender las esencias verdaderas de los entes, precisamente gracias a su no limitación, a su no especialización, solo las formas científicas limitadas, especializadas de la ciencia nos permiten actuar con garantías sobre ellos. La especialización y la limitación, en efecto, son las claves de la ciencia a lo largo de su historia. Es tanto lo adquirido a 
través de la especialización científica que desde hace tiempo una sola mente no es capaz de abrazar todo el conocimiento producido por la ciencia, ni siquiera en sus líneas básicas. La sociología del conocimiento científico, al estudiar su especialización obligada frente a saberes más universales, acaba indicándonos que la formación científica es tanto menor a escala individual cuanto mayor es a escala de la sociedad en su conjunto, y que, en consecuencia, sería muy importante cultivar al tiempo modos de aprehender la realidad inicialmente más totalizadores; conocimientos que, en buena medida, nos facilitasen un mejor estar en el mundo, un mejor posicionarnos frente a los entes y los hechos; en definitiva, un mejor "tener criterio". En todo caso, la forma más amplia de conocimiento, no necesariamente una sola, debe ser no científica, porque las restricciones que impone el método de la ciencia impiden justo la generalidad. Es decir, lo característico del método científico hace que el conocimiento ofrecido por él sea particular, y que no pueda suplantar formas tradicionales, pre-cientí- ficas, de conocimiento, las cuales al parecer sí logran abarcar, por la naturaleza de su proceder, lo general. Como será fácil concluir de estas reflexiones, abogamos claramente por la pluralidad del conocimiento del mundo, pues el ser humano individual necesita tipos tanto generales como especializados, no científicos y científicos, de saber, para habitar ese mundo y, llegado el caso, para transformarlo apropiadamente. $Y$ para evitar que, conforme el mundo se escudriña con la lente de la ciencia, el conocimiento acumulado pase por nosotros como pasa el agua por la roca emplazada en medio de un río.

\section{AGRADECIMIENTOS}

Este trabajo ha sido financiado por los proyectos BFU2012-39816-CO2-01 y SAF2012-31187 del Ministerio de Economía y Competitividad, y cofinanciado por FEDER, Prometeo/2009/092 de la Generalitat Valenciana y por los proyectos ST-FLOW e ITN MarieCurie Symbiomics de la Unión Europea.

\section{BIBLIOGRAFÍA}

Castrodeza, C. (2010). La darwinización del mundo. Barcelona: Herder.
Fernández Liria, C. (2012). ¿Para qué servimos los filósofos? Madrid: Los Libros de la Catarata.
Heidegger, M. (1999). Introducción a la filosofía. Madrid: Cátedra. 